Acta bot. bras. 1(2):275-285 (1988) supl.

\title{
ANATOMIA FOLIAR DE EUGENIA SULCATA SPRING EX MART. (MYRTACEAE)
}

\author{
Raul D. Machado (1)
}

Cecília G. Costa (2)

Gerusa B. Fontenelle (3)

\begin{abstract}
RESUMO - A lâmina foliar de Eugenia sulcata Spring ex Mart. é analisada, ressaltando-se aspectos de suas epidermes, à luz da microscopia óptica e da microscopia eletrônica de transmissão e de varredura. As paredes anticlinais destas células são sinuosas e as periclinais externas têm espessura não uniforme, em decorrência de projeçöes internas destas paredes. Ao microscópio eletrônico de transmissão tais paredes apresentam-se constituidas por 3 camadas distintas. $\mathrm{O}$ microscópio eletrônico de varredura mostra completa ausência de estriaçōes na superfície externa da epiderme abaxial. Os estômatos são classificados como anomoestaurocíticos quanto ao número e arranjo das células subsidiárias e considerados graminóides em função do espessamento desigual das células estomáticas. A lâmina foliar tem estrutura dorsiventral, ocorrendo no mesofilo bolsas secretoras em posição subepidérmica.
\end{abstract}

ABSTRACT - The leaf blade of Eugenia sulcata Spring ex Mart. is examined with special attention to the epidermis, using light and electron microscopy (transmission and scanning). The anticlinal walls of the adaxial epidermis are wavy and the external periclinal walls do not have a uniform thickness on account of internal projections. Transmission electron microscopy shows in this wall three distinct layers. Scanning electron microscopy demonstrates that the outer surface of the abaxial epidermis does not exhibit striations. Number and arrangement of subsidiary cells permit the stomata to be classified in the anomostaurocytic type; according to the unequal thickening of guard cells they can be considered graminoid. The leaf blade is dorsiventral and includes subepidermic secretory cavities.

Key-words: Myrtaceae, leaf anatomy.

\section{Introdução}

A familia Myrtaceae é uma das mais representativas das restingas brasileiras, não só pelo grande número de espécies, como pela importância e utilização de muitas, dado seu valor ornamental, alimentício ou medicinal.

Entretanto, como ressalta Barroso (1984), as espécies americanas das Myrtaceae são muito semelhantes morfologicamente, o que dificulta sobremaneira o trabalho de sua identificação.

Com a finalidade de solucionar problemas dessa natureza, a Sistemática vem lançando mão de outros ramos da ciência botânica e a esse respeito os estudos anatômicos têm-se revelado de grande valia. Assim, a observação de características epidérmicas, tais como o arranjo e a forma das células, aspecto de suas paredes anticlinais, relevo dos limites celulares, curvatura das paredes periclinais externas, escultura cuticular, secreçōes epicuticulares, tipos de estômatos, etc., conduzem muitas vezes a resultados conclusivos em termos de diagnóstico genérico e específico (Barthlott 1981).

\footnotetext{
(1) - Instituto de Biofísica - UFRJ - Centro de Ciências da Saúde - Bloco G. Ilha do Fundão, Cidade Universitária, 21941 Rio de Janeiro, RJ, Brasil. Bolsista do CNPq.

(2) - Jardim Botânico do Rio de Janeiro - Bolsista do CNPq.

(3) - Instituto de Biologia - Deptº de Botânica - UFRJ - Bolsista do CNPq.
} 
Numa tentativa de fornecer subsídios que auxiliem o taxonomista no trabalho de identificação das Myrtaceae, deu-se início ao estudo anatômico de representantes da familia ocorrentes nas restingas do Estado do Rio de Janeiro, selecionando como ponto de partida, o gênero Eugenia L., citado por Araujo e Henriques (1984) como possuidor de maior número de espécies.

Este trabalho representa os primeiros resultados obtidos e compreende uma análise anatômica da lâmina foliar de Eugenia sulcata, ressaltando-se determinados aspectos estruturais de sua epiderme.

\section{Material e Métodos}

O material utilizado no presente trabalho é procedente da restinga de Marambaia, Rio de Janeiro, e acha-se registrado no herbário do Departamento de Botânica da UFRJ, sob o $n=21673$.

Foram coletadas folhas completamente desenvolvidas, expostas ao sol, fixadas em F.A.A., em álcool etilico a $70^{\circ}$ (Johansen 1940). Algumas foram conservadas em álcool $70^{\circ}$ para posterior observação.

O estudo de epiderme foi realizado em material dissociado pelo método de Jeffrey (Jensen 1962) corado pela safranina hidroalcoólica, como também através de cortes paradérmicos feitos à mão livre.

Os testes histoquímicos foram aplicados em cortes manuais de material fresco para detectar a ocorrência de tanino, utilizando-se o teste de Hoepfner-Vorsatz (Reeve 1951) e de compostos de origem lipídica, pelo uso do Sudan TV (Sass 1951).

As preparações definitivas para a observação ao microscópio óptico (MO) foram realizadas segundo Johansen (1940) e após desparafinadas e hidratadas foram coradas pelo azul de astra e fucsina básica, modificado segundo Krieger (apud Braga 1977).

Para a mesma finalidade, foram utilizados cortes semifinos, obtidos ao ultramicrótomo Porter-Blum, coradas com azul de toluidina e processados de acordo com a mesma metodologia seguida para as preparações destinadas ao microscópio eletrônico de transmissão (MET), que será detalhada a seguir.

O material analisado ao MET foi preparado utilizando pequenas tiras da lâmina foliar, da região mediana, com cerca de $1 \mathrm{~mm}$ de largura, fixadas em glutaraldeido a $5 \% \mathrm{em}$ tampão cacodilato de sódio $0.05 \mathrm{M}$ contendo $5 \mathrm{mM}$ de cálcio, por cerca de $24 \mathrm{~h}$ à temperatura ambiente. Em seguida o material foi lavado na solução tampão e pós-fixado em tetróxido de ósmio a $2 \%$ em cacodilato. $0.05 \mathrm{M}$ com Ca5mM, desidratado em concentrações crescentes, de acetona e incluindo em meio de Spurr (Hayat 1981). Após obtenção dos cortes ultrafinos, estes foram corados com permanganato de potássio e citrato de chumbo e examinados no aparelho JEOL 100-Cx.

Para exame de microscópio eletrônico de varredura (MEV), fragmentos de folhas herborizadas receberam uma cobertura de ouro, sendo em alguns casos previamente fervidas em clorofórmio, com a finalidade de remover a cera superficial.

As fotomicrografias foram obtidas aos microscópios binoculares Olympus $\mathrm{BH}$ e Zeiss-Universal e as eletromicrografias, aos microscópios eletrônicos de transmissão e de varredura, respectivamente JEOL 100-Cx e 25-S-II.

Os desenhos foram executados ao microscópio binocular Zeiss, com auxllio da câmara clara e as escalas projetadas com a mesma combinação óptica.

Fig. 1 - Aspecto geral da epiderme abaxial, revelando discreta ondulação das paredes periclinais externas, após remoção da cera superficial pelo clorotórmio. Eletromicrografia ao MEV. 860 X. Fig. 2 - Vista frontal da epiderme adaxial de $E$. sulcata, mostrando interdigitaçōes entre as ćlulas adjacentes e regiōes mais escuras que correspondem às áreas menos espessas da parede periclinal externa. Fotomicrografia em contraste interferencial de Nomarski. 780 X. Fig. 3 - Corte transversal da lâmina foliar, evidenciando as projeçōes parietais da epiderme adaxial em direção ao lume. O contraste de fase acentua na parede externa, duas camadas de densidades diferentes, correspondendo, possiveimente, a mais densa, às camadas cutinizadas. Fotomicrografia em contraste de fase. 900X. 


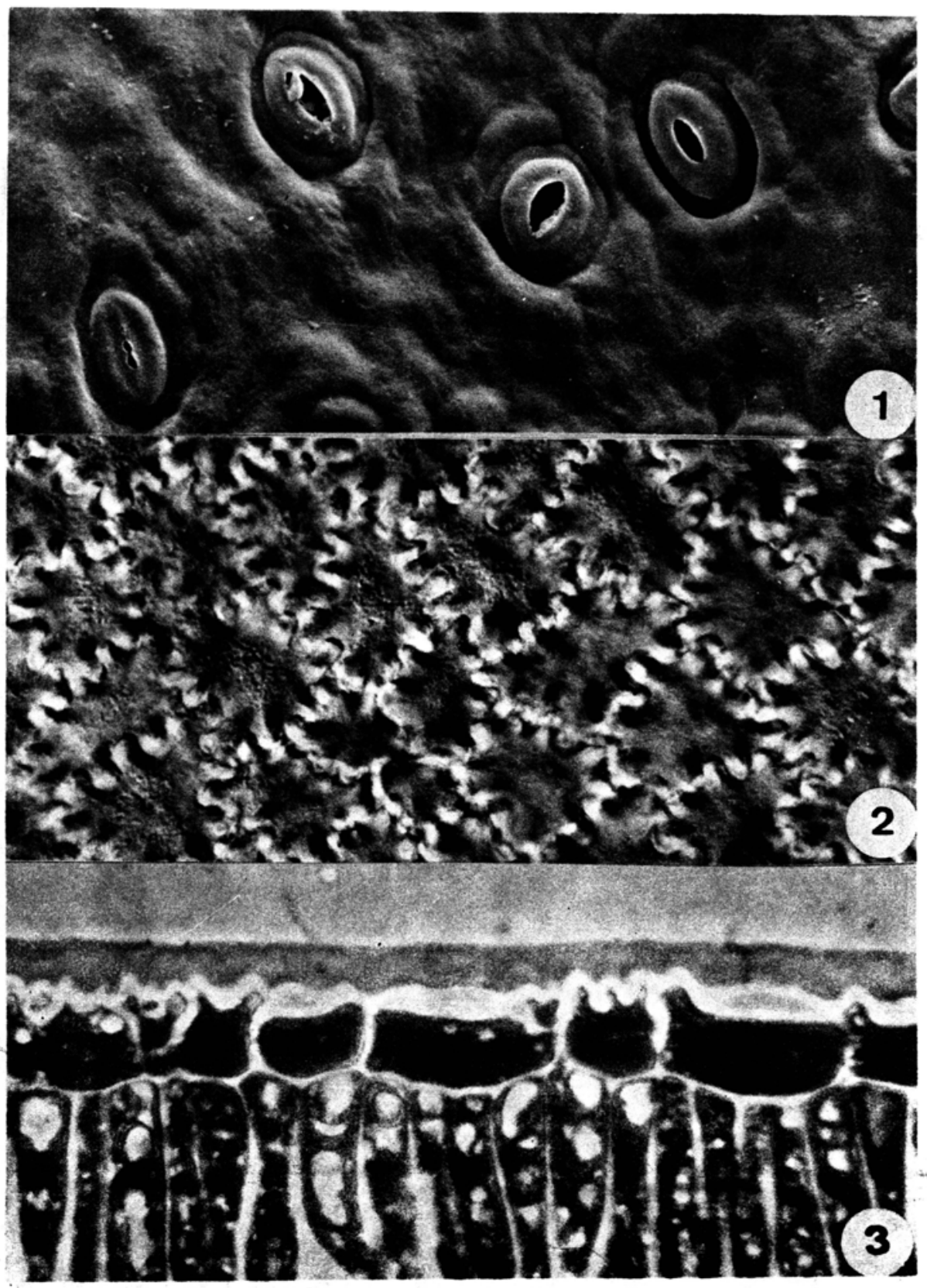




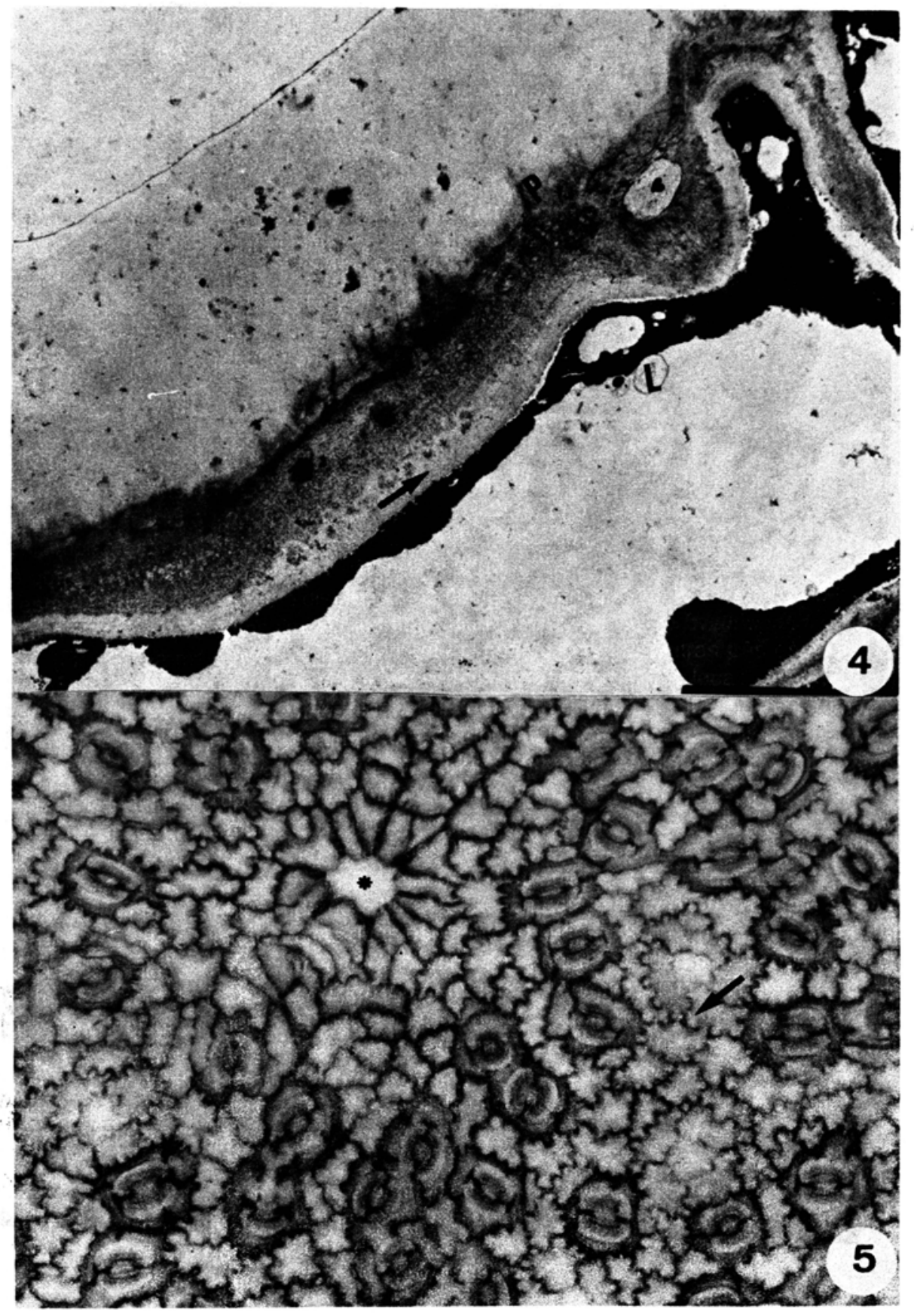




\section{Resultados}

O MEV revela que as duas epidermes de $E$. sulcata apresentam superfície lisa. $\mathrm{Na}$ epiderme abaxial após remoção da cera superficial, observa-se apenas uma discreta ondulação resultante da curvatura das paredes periclinais externas (Fig. 1).

A epiderme da lâmina foliar de $E$. sulcata, quando observada frontalmente, apresenta paredes anticlinais sinuosos, tanto na face adaxial como na abaxial, ao nivel da região intercostal e das margens, exceto sobre as nervuras principal e de médio porte, onde a forma das células tende para retangular e seu arranjo acompanha o curso dessas nervuras. Tais sinuosidades são acentuadas que se assemeiham a interdigitações entre as células adjacentes (Fig. 2).

A análise de seções transversais semifinas da lâmina foliar revela a ocorrência de projeções internas das paredes periclinais externas, conferindo um contorno irregular ao lume celular a este nivel (Fig. 3). O conteúdo celular se acomoda ao relevo interno, de modo a preencher os espaços entre as projeções. Consequentemente, a espessura das paredes periclinais externas das células epidérmicas é desigual, o que propicia a observação, em vista frontal, de áreas mais claras que correspondem aos intervalos entre as projeções, ou seja, a região menos espessas da parede celular (Fig. 5). Essas áreas mostram-se escuras quando observadas em contraste interferencial de Nomarski, conforme evidenciado na figura 2 que representa a visão frontal da epiderme adaxial, em corte paradérmico.

Através de cortes ultrafinos vê-se claramente no MET, que a parede periclinal externa das células epidérmicas apresenta pelo menos 3 camadas distintas. Uma contígua ao lume é menos eletrodensa e sua espessura é da ordem de 0,5 - 0,6 um. Segue-se outra com evidente depósito eletrodenso que se projeta a intervalos (Fig. 4-P) na camada mais externa, que é bastante homogênea e eletronluscente, com espessura de 5,5 - 6 um. A desigualdade de textura dessa parede é observada como uma granulosidade discreta pelo $\mathrm{MO}$, em seções paradérmicas (Fig. 2).

Nas duas epidermes, observam-se também células cujas paredes apresentam sinuosidade menos acentuada (Fig. 5, asterisco) em torno da qual os demais elementos por vezes se dispõem radialmente. Tais células tomam coloração menos intensa pela safranina e pelo Sudan IV e nelas não se notam as áreas mais claras, provavelmente em decorrência da espessura mais homogênea de suas paredes. A observação de seções paradérmicas revela que as células descritas estão relacionadas a cavidades secretoras subjacentes à epiderme (Fig. 6, asterisco).

Os estômatos ocorrem isolados ou em grupos que se distribuem ao acaso, na epiderme abaxial (Fig. 5). As células estomáticas apresentam um espessamento cutinizado em toda a extensão, exceto ao nível polar, o que confere ao estômato o aspecto graminóide (Fig. 8).

No entanto, analisando o arranjo das células subsidiárias em relação às estomáticas, ajustam-se ao tipo anoestaurocítico (Figs. 5 e 8).

Seções transversais atingindo as células estomáticas ao nível equatorial revelam que suas paredes são notavelmente espessas o que lhes confere lume reduzido a este nível, conforme mostra a figura 9. Esta figura evidencia ainda que as paredes periclinais ex-

Fig. 4 - Eletromicrografia obtida ao MET de corte ultrafino, abrangendo a parede periclinal externa da epiderme adaxial. Nota-se uma camada menos eletrodensa (seta) contígua ao lume celular (L), seguindo-se uma outra impregnada de material denso com projeções $(P)$ penetrando na terceira camada, esta homogênea e eletronluscente. 7000 X. Fig. 5 - Vista frontal da epiderme abaxial de $E$. sulcata, evidenciando a sinuosidade das paredes anticlinais, as áreas claras (seta) decorrentes da espessura não uniforme das paredes periclinais, distribuição dos estômatos, aspecto das células subsidiárias e células de topo da cavidade secretora subjacente (asterisco) em torno das quais os demais elementos epidermicos se dispōem radialmente. $350 \mathrm{X}$. 
ternas das células subsidiárias também são espessas e que as camadas cutinizadas apresentam um espessamento mais acentuado ao nivel das células estomáticas, projetando-se sobre o ostiolo em duas cristas proeminentes. $O$ espessamento celulósico das parades periclinais, assim como das camadas cutinizadas é visto também em corte longitudinal da célula estomática (Fig. 10).

$\mathrm{Na}$ junção das células estomáticas, ao nível polar, observa-se um discreto espessamento cutinizado em T. As células subsidiárias, em número de 3-5, apresentam conteúdo mais denso de natureza tânica e suas paredes periclinais externas são bastante espessas, com superfície granulosa.

Gotas lipídicas ocorrem nos elementos epidérmicos de ambas as faces da lâmina foliar de E. sulcata, sobressaindo por suas maiores dimensões nas células estomáticas e subsidiárias.

A figura 7 que representa a seção transversal da lâmina foliar de $E$. sulcata revela sua estrutura dorsivental. As epidermes, assim como o parênquima paliçádico são uniestratificadas, se bem que as célular deste último, em alguns trechos, se apresentem divididas por paredes transversais.

A mesma figura evidencia que o parênquima paliçádico ocupa cerca de 1/4 da espessura total do mesofilo, ocorrendo entre eles e o lacunoso, uma camada de células de transição.

O parênquima lacunoso é integrado por células de forma irregular, em torno de 8-10 estratos, entre as quais se localizam os espaços intercelulares e as lacunas características do tecido.

$\mathrm{Na}$ margem foliar, as células paliçádicas tornam-se mais curtas e são interrompidas por elementos colenquimáticos, de paredes relativamente delgadas. A este nível, as lacunas são menos evidentes e as projeções parietais das paredes periclinais externas das células epidérmicas são mais conspícuas (Fig. 11).

Nas camadas subjacentes às duas epidermes, estão situadas bolsas secretoras subcirculares, dotadas de um tecido epitelial integrado por uma camada celular de paredes delgadas (Fig. 7). As bolsas da face adaxial às vezes têm aspecto piriforme. Seções paradérmicas revelam que os elementos do lacunoso se dispõem radialmente em torno de algumas dessas estruturas, o que se observa melhor quando as mesmas são seccionadas em seu plano mediano (Fig. 6). Entre as bolsas da face adaxial e a epiderme, ocorre uma célula tabular, portadora de conteúdo tânico denso, melhor evidenciada em cortes transversais semifinos passando pelo plano equatorial das mesmas (Fig. 7). Já as bolsas da face abaxial estão situadas imediatamente abaixo da camada epidérmica.

O feixe vascular da nervura principal ao nívél do terço médio é do tipo bicolateral, acompanhado parcialmente por esclerênquima. O floema externo é mais abundante e em forma de arco, enquanto o floema interno distribiu-se em pequenos grupos separados por células de parênquima. O xilema mostra seus elementos dispostos em série radial.

Nas nervuras de médio e pequeno porte, os feixes vasculares são do tipo colateral. Aquelas se encontram envolvidas parcialmente por um tecido esclerenquimatoso, enquanto nas nervuras menores ocorre apenas uma bainha parenquimática.

Evidenciou-se também a presença constante de compostos fenólicos (tanino) nos elementos parenquimáticos relacionados aos feixes vasculares, a saber: parênquima floemático e radial e na bainha dos feixes menores, assim como nas epidermes e no clorênquima. Idioblastos cristalíferos contendo drusas e gotas lipídicas são frequentes no mesofilo.

Fig. 6 - Fotomicrografia de um corte paradérmico da face abaxial, evidenciando o perfil subcircular das bolsas secretoras. Observa-se a disposição radial das células circundantes do mesofilo em torno de um desses elementos $(+)$ e a forma diferente da célula de topo (asterisco). Săo bem visíveis as gotas lipídicas (seta) das células subsidiárias. 345 X. Fig. 7 - Seção transversal da lâmina foliar de E. sulcata, mostrando sua estrutura dorsiventral, as epidermes em um só estrato e as bolsas secretoras do mesofilo. Fotomicrografia em contraste de fase. $290 \mathrm{X}$. 

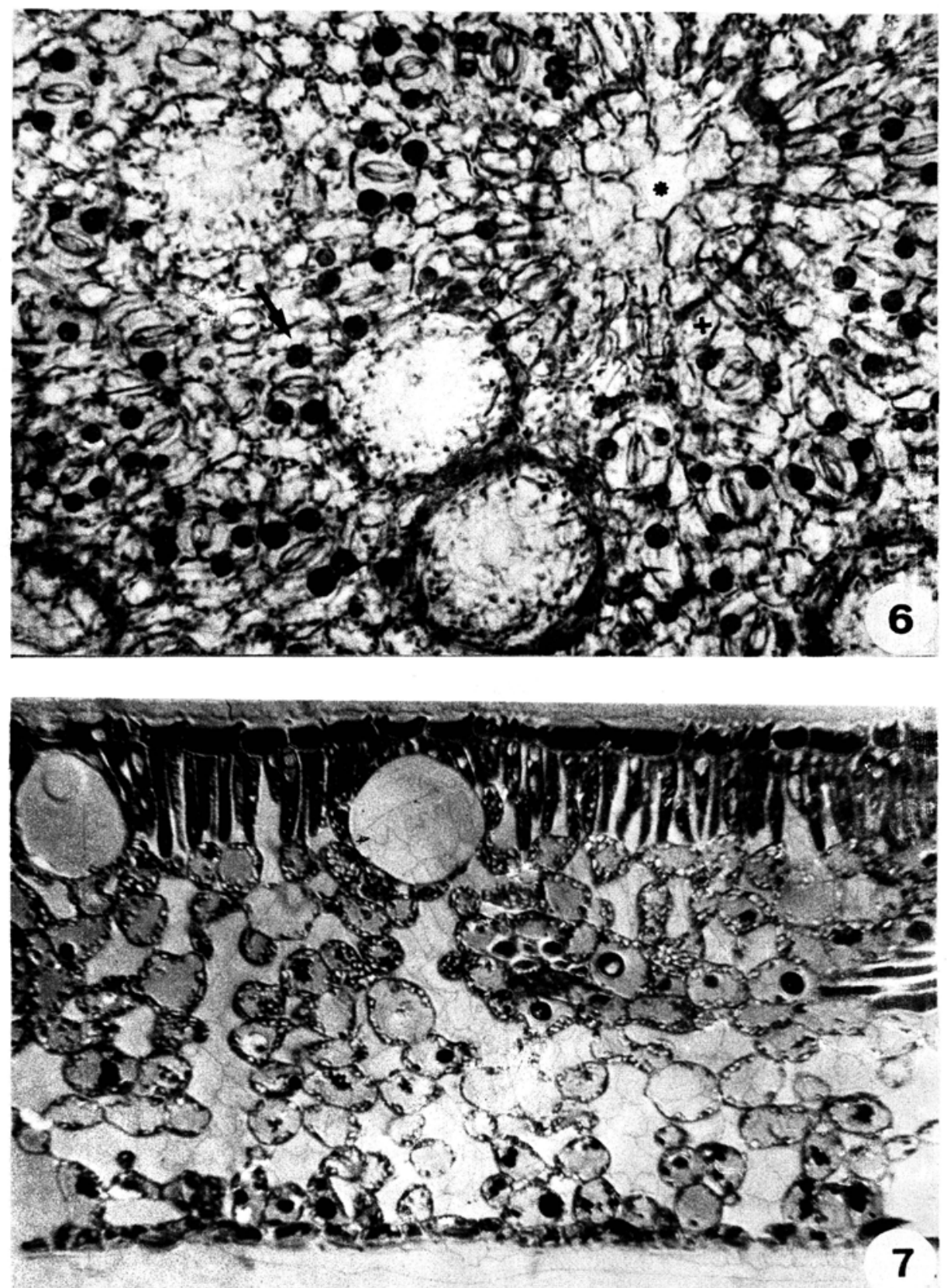

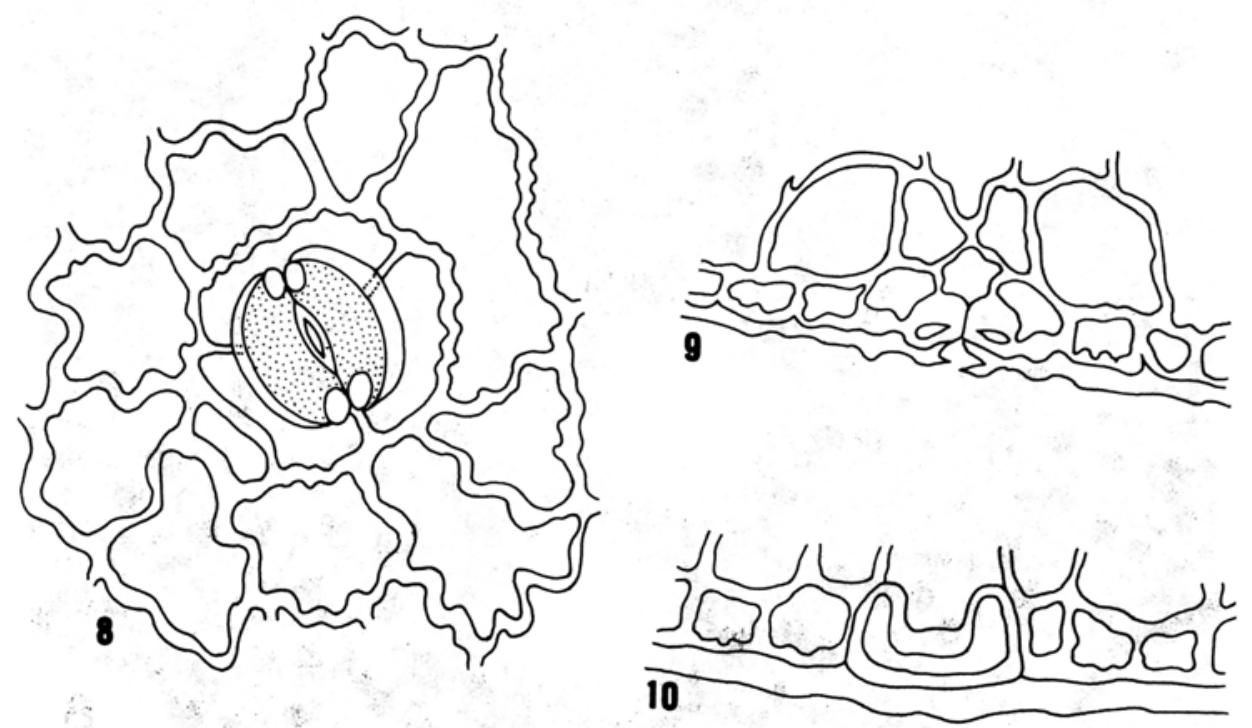

$100 \mu \mathrm{m}$

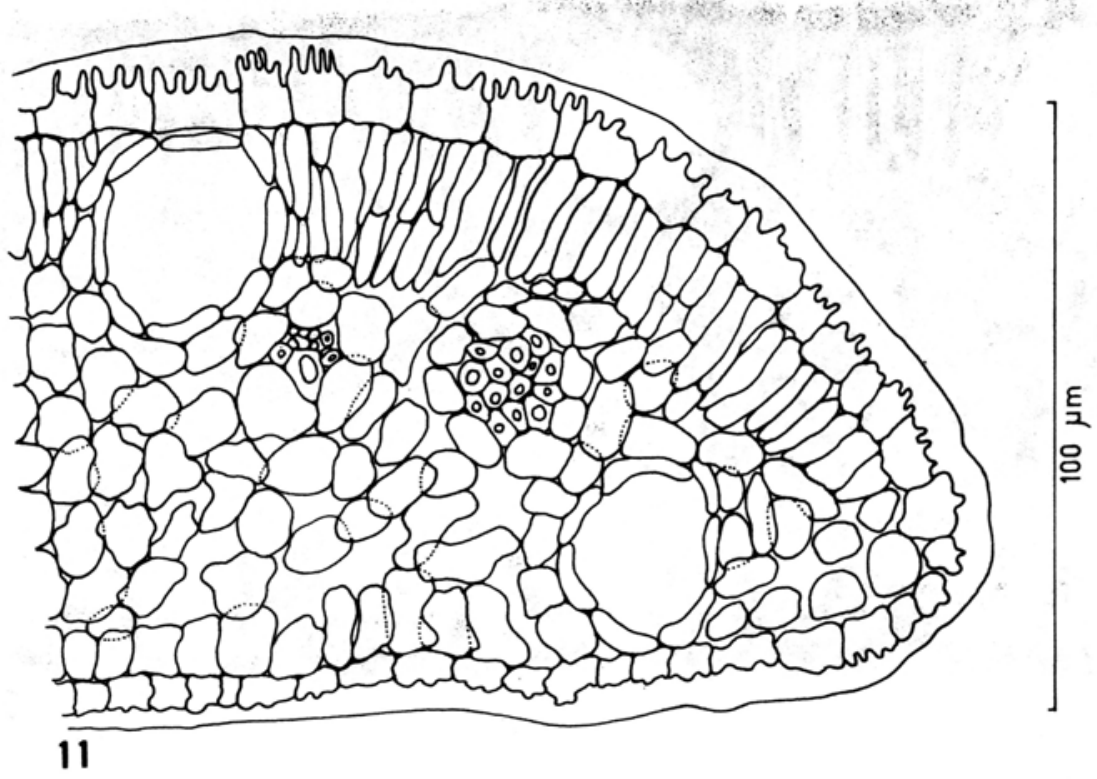




\section{Discussão e Conclusóes}

Alguns dos aspectos evidenciados em Eugenia sulcata, como cavidades secretoras em posição subepidérmica e a presença constante de compostos tânicos nas células não esclerenquimatosas, vêm corroborar o que Metclafe e Chalk (1965) mencionam como peculiares à famnila Myrtaceae.

Esses autores citam ainda a ocorrência de feixes bicolaterais em Eugenia e outros gêneros da famnia. Em $E$. sulcata confirmou-se a presença desses feixes ao nível da nervura mediana da lâmina foliar, assim como do mesofilo dorsiventral, também apontado por aqueles autores para o referido gênero.

Metcalfe e Chalk (1965) mencionam ainda que fibras esclerenquimáticas e células pétreas caracterizam as espécies de Eugenia. Na espécie em estudo evidenciou-se um acompanhamento de esclerênquima nos feixes das nervuras principal e de médio porte. Entretanto, não foram observadas células pétreas no material examinado. Nas nervuras de médio e pequeno porte, foi constante a presença de uma bainha parenquimatosa, fato não mencionado pelos autores em causa.

Cristais isolados ou aglomerados são também citados para as espécies do gênero. Em E. sulcata apenas cristais aglomerados sob a forma de drusas foram evidenciados no mesofilo.

Os estômatos das Myrtaceae têm sido descritos como paracíticos (Bandulskà 1931) e anomocíticos (Mecalfe \& Chalk 1965). Johnson (1980) além destes tipos refere também o tipo ciclocítico. Van Vyk et al. (1982) discutido os parâmetros utilizados na definição de células subsidiárias, concluem que as espécies africanas de Eugenia são possuidoras de autênticas células subsidiárias e sugerem o termo anomoestaurocítico como o mais apropriado para designar os estómatos dessas espécies. Os estômatos de $E$. sulcata ocorrem na epiderme abaxial e são acompanhados por 3-5 células subsidiárias, que diferem das demais por seu conteúdo mais denso em compostos fenolicos (tanino) e pela presença de grandes gotas lipídicas, o que vem ao encontro da definição topográfica de célula subsidiária (Wilkinson 1979). No que diz respeito à disposição destas células em relação às estomáticas, os estômatos de $E$. sulcata podem também ser considerados anomoestaurocíticos, de acordo com a descrição de Van Vyk et al. (1982).

Entretanto, analisando as características das células guardiãs desta espécie quanto ao espessamento parietal, mais pronunciado na região equatorial e praticamente ausente nos polos, pode-se qualificá-los como pertencentes ao tipo graminóide, mencionado.por Braga (1984) para várias espécies de Dicotiledôneas, inclusive uma espécie de Myrtaceae, Myrcia amazonica D.C.

Banduslka (1931) alude a um espessamento cutinizado em T nos polos das células estomáticas de espécies fósseis e recentes da familia Myrtaceae. Johnson (1980) observou esse mesmo caráter nas células guardiãs de espécies de Leptospermum, gênero de Myrtaceae ocorrente na Austrália, concluíndo por sua validade como caráter diferencial a nivel específico. Trabalho em andamento sobre as Myrtaceae das restingas do Rio de Janeiro, tem revelado que essa característica, embora variável, é também constante nas espécies de Eugenia até agora estudadas e provavelmente poderá servir como subsídio à sua identificação.

As sinuosidades das paredes anticlinais das células epidérmicas de $E$. sulcata correspondem ao tipo $U$, segundo Barthlott (1981), ao referir-se às características espidérmicas dos vegetais.

Fig. 8 - Detalhe de um estómato em vista frontal. São evidenciados o espessamento das células estomáticas e o arranjo das células subsidiárias. Fig. 9 - Representação da seçăo transversal das células estomáticas ao nivel equatorial, evidenciando o espessamento de suas paredes e as cristas cutinizadas. Observase ainda, a espessura acentuada das paredes periclinais externas das células subsidiárias. Fig. 10 - Corte longitudinal passando por uma das células estomáticas. O espessamento celulósico das paredes periclinais é evidente, assim como o lume amplo ao nível polar. Fig. 11 - Seçăo transversal da margem foliar. 
O MEV revela que a cutícula adaxial de E. sulcata é lisa, mesmo após fervura no clorofórmio, de onde se conclui que o relevo observado ao $\mathrm{MO}$ corresponde à espessura desigual da parede periclinal externa, em sua face interna. A cutícula abaxial é também lisa, apenas com leve ondulação pela curvatura das paredes externas, o que se verifica após extração da delgada camada de cera pelo clorofórmio. O trabalho em andamento já referido mostrou que em outras espécies do mesmo gênero, podem ocorrer características bem distintas, tais como evidente estriação de ambas as cutículas em material ao natural.

Pate e Gunning (1969) têm-se referido a células com projeçōes internas da parede secundária, esclarecendo que tais projeçōes constam de material não lignificado, depositado no lado interno da parede primária não especializada e que podem ocorrer em toda a periferia celular ou estarem restritas a determinadas regiōes. Essas células, chamadas de "células de transferência" foram relacionadas com o transporte de solutos à curta distância ou com a absorção ou secreção de solutos em relação ao ambiente externo.

As células de transferência têm sido descritas em várias situaçōes inclusive nas paredes anticlinais de células epidérmicas de Ranunculus fluitans (Gunning \& Pate 1969).

As projeções parietais das células epidérmicas de $E$. sulcata foram também detectadas em outras espécies do mesmo gênero, observadas até o momento. Em todos os casos são evidenciadas ao MO mesmo em cortes feitos à mão livre, sem qualquer tratamento especial, o que não condiz com as referências dos autores citados, segundo os quais as projeções parietais das células de transferência são melhor evidenciadas em cortes ultrafinos e com o recurso da mičroscopia eletrônica. Assim sendo e na falta de dados mais conclusivos, prefere-se deixar o assunto em suspenso, até que os estudos em andamento possam revelar a significação das aludidas projeçōes.

A granulosidade fina das paredes periclinais externas, provavelmente corresponde à textura da porção celulósica dessas paredes. Martin e Juniper (1970) fazem menção a projeções fibrilares da parede celulósica no interior da cutícula, exemplificando com uma foto do gênero Eucalyptus.

Quanto às bolsas secretoras de Eugenia sulcata, serão objeto de estudo mais acurado a nível ontogenético. No entanto, pode-se constatar que elas ocorrem abaixo das duas epidermes, acreditando-se que seu formato diferente nas duas faces, seja decorrente das pressões desiguais a que foram sujeitas no curso de seu desenvolvimento, dado o maior ou menor grau de compacidade dos tecidos adjacentes (paliçádico e lacunoso).

$\mathrm{Na}$ espécie em estudo, parece haver uma relação entre as bolsas secretoras e uma célula epidérmica que, por seu aspecto e conteúdo se diferencia das demais que se dispōem radialmente em torno daquela. Pereira (1985) refere-se a 1-2 células de conteúdo denso e paredes mais espessas, em estreita correlação com as bolsas de $E$. nitida Camb. Peculiaridades semelhantes foram evidenciadas por Johnson (1980) em várias espécies de Leptospermum.

\section{Referências Bibliográficas}

ARAUJO, D.S.D. \& HENRIQUES, R.P.G. 1984. Análise florística das restingas do Estado do Rio de Janeiro. In: LACERDA, L.D. et.al. Restingas; origem, estrutura, processos. Niteró, CEUFF.

BARROSO, G.M., GUIMARÄES, E.F., ICHASO, C.L.F., COSTA, C.G., PEIXOTO, A.L. 1984. Myrtaceae. In: Sistemática de Angiospermas do Brasil. Vol. II. Viçosa. Imprensa Universitária da Universidade Federal de Viçosa - MG.

BANDULSKA, H. \& A.R.C.S. 1931. On the cuticles of some recent and fossil Myrtaceae. J. Linn. Soc. (Bot) 48:657-671.

BARTHLOTT, W. 1981. Epidermal and seed surface characters of plants: Systematic applicability and some evolutionary aspects. In: Benke, H. Ultrastructure and systematics of seed Plants. Nord. J. Bot. I(3):345-354.

BRAGA, M.M.N. 1977. Anatomia foliar de Bromeliaceae da Campina. Acta Amazonia. 7(3):5-74.

BRAGA, M.M.N. 1984. Sobre a ocorrência dos estómatos "graminoides" em espécies do gênero Virola e em outras Dicotiledóneas. Acta Amazonica. 14 (3-4):521-525. 
GUNNING, B.E.S. \& PATE, J.S. 1969. “Transter cells”. Plant cells with wall ingrowths, specialized in relation to short distance transport of solutes - their occurence, structure, and development. Protoplasma 68:107-133.

HAYAT, M.A. 1981. Principles and Techniques of electron microscopy-Biological Applications. Edward Arnold. Longon.

JENSEN, W.A. 1962. Botanical Histochemistry (Principles Practice), W.H. Freeman and Company. São Francisco.

JOHANSEN, D.A. 1940. Plant Microtechnique. McGraw-Hill Book Co. Inc. New York.

JOHNSON, C.T. 1980. The leaf anatomy of Leptospermum Forst. Aust. J. Bot. 28:77-104.

MARTIN, J.T. \& JUNIPER, B.E. 1970. Cuticles of Plants. Edinburgh, R. \& R. Clark, Ltd. Oxford.

METCALFE, C.R. \& CHALK, R. 1965. Myrtaceae. In: Anatomy of the Dicotyledons. Oxford. Clarendon Press vol I: 620-631.

PATE, J.S. e GUNNING, B.E.S. 1969. Vascular transfer cells in angiosperm leaves. A taxonomic and morphological survey. Protoplasma, 68:135-156.

PEREIRA, A.M. DE C. 1985. Anatomia foliar de Eugenia nitida Camb. (Myrtaceae). Dissertação de Mestrado, UFRJ.

REEVE, R.M. 1951. Histochemical tests for polyphenols in plant tissues. Stain Tech., Geneve - New York, 26(2):91-96.

SASS, J.E. 1951. Elements of Botanical Microtechnique. McGraw-Hill Book Co. Inc. New York -London.

VAN VYK, A.E., ROBBERTSE, P.J. \& KOK, P.D.F. 1982. The genus Eugenia L. (Myrtaceae) in Southern Africa: the structure and taxonomic value of stomata. J. Linn Soc. (Bot). 84:41-56.

WILKINSON, H.P. 1979. The plant surface (mainly leaf) Part I: Stomata In: METCALFE, C.R. \& CHALK, R. Anatomy of the Dicotyledons. 2 end. Ed. Oxford. Clarendon Press. Vol. I:97-117.

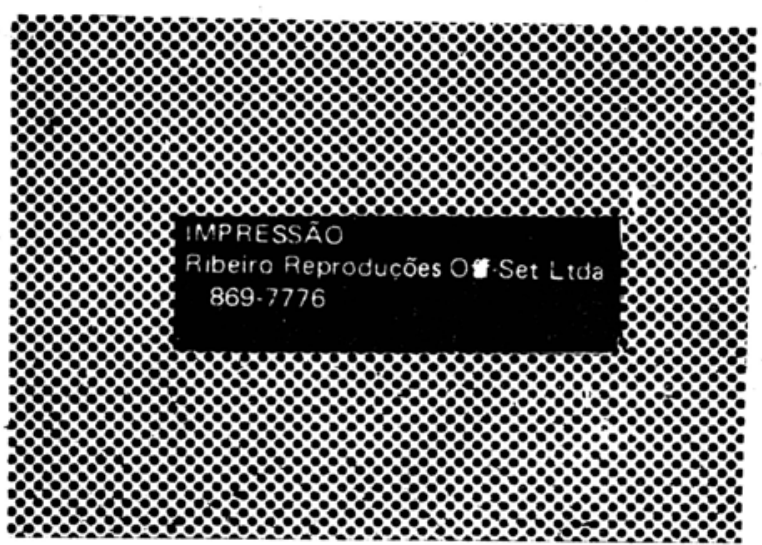

